\title{
Lenalidomide-Induced Hyperthyroidism during Treatment for Anaplastic multiple myeloma: A Case Report
}

\author{
Authors: Mazhar Dalvi ${ }^{1}$, Faisal Dalvi ${ }^{2}$ \\ Hospital: Department of Endocrinology and Diabetes ,Al Noor Hospital ${ }^{1}$,Aster Medical Centre ${ }^{2}$,United Arab Emirates.
}

Lenalidomide ,a thalidomide derivative has immunomodulatory , antiangiogenic and anticancer properties(1).Lenalidomide has significantly improved survival in myeloma although side effects and toxicity do occur.

We report a case of thyroiditis with hyperthyroidism in a patient receiving lenalidomide in treatment for anaplastic multiple myeloma.
\end{abstract}

64 year old female with anaplastic multiple myeloma but no history of thyroid disease received Lenalidomide 25 mg once daily orally for 21 days of repeated 28-day cycles.

She developed hyperthyroidism during the course of the treatment, with TSH of $0.003 \mathrm{mIU} / \mathrm{mL}(0.35-4.94 \mathrm{mIU} / \mathrm{mL})$ decreasing from a normal baseline of $0.93 \mathrm{mIU} / \mathrm{mL}$ two months prior. Free T4 and Free $\mathrm{t} 3 \mathrm{was}$ elevated at $2.25 \mathrm{ng} / \mathrm{dl}(0.7-1.8$ $\mathrm{ng} / \mathrm{dl})$ and $5.01 \mathrm{pg} / \mathrm{ml}(1.7-3.7 \mathrm{pg} / \mathrm{ml})$ respectively.

There were no interim medication changes, recent contrast CT, viral illness, amiodarone or interferon treatment. Patient denied overt hyperthyroid symptoms, with stable vital signs , unremarkable physical exam (no exophthalmos, thyromegaly or palpable thyroid nodules, normal reflexes).

The creatinine went up to $1.7 \mathrm{mg} / \mathrm{dl}$ from baseline of $0.6 \mathrm{mg} / \mathrm{dl}(0.6-1.1 \mathrm{mg} / \mathrm{dl})$. Lenalidomide was implicated and was discontinued for 6 weeks.After 6 weeks, TSH spontaneously normalized to $1.34 \mathrm{mIU} / \mathrm{mL}$, and creatinine improved to $1.1 \mathrm{mg} / \mathrm{dl}$, lenalidomide was restarted at reduced dose of $20 \mathrm{mg}$ daily. Two weeks later, TSH dropped to $0.005 \mathrm{mIU} / \mathrm{mL}$, FT4 increased to $2.27 \mathrm{ng} / \mathrm{dL}$.

Further work-up:TSH receptor antibodies (Trabs): normal, Thyroidperoxidase antibodies and Thyroglobulin antibodies: normal

Thyroglobulin $800 \mathrm{ng} / \mathrm{mL}(1-50 \mathrm{ng} / \mathrm{ml})$.ESR $82(<30)$.

Thyroid ultrasound showed a heterogeneous gland and findings were suggestive of thyroiditis( Image 1).

Thyroid pertechnetate scan showed minimal uptake, suggesting Lenalidomide-induced thyroiditis(Image 2)

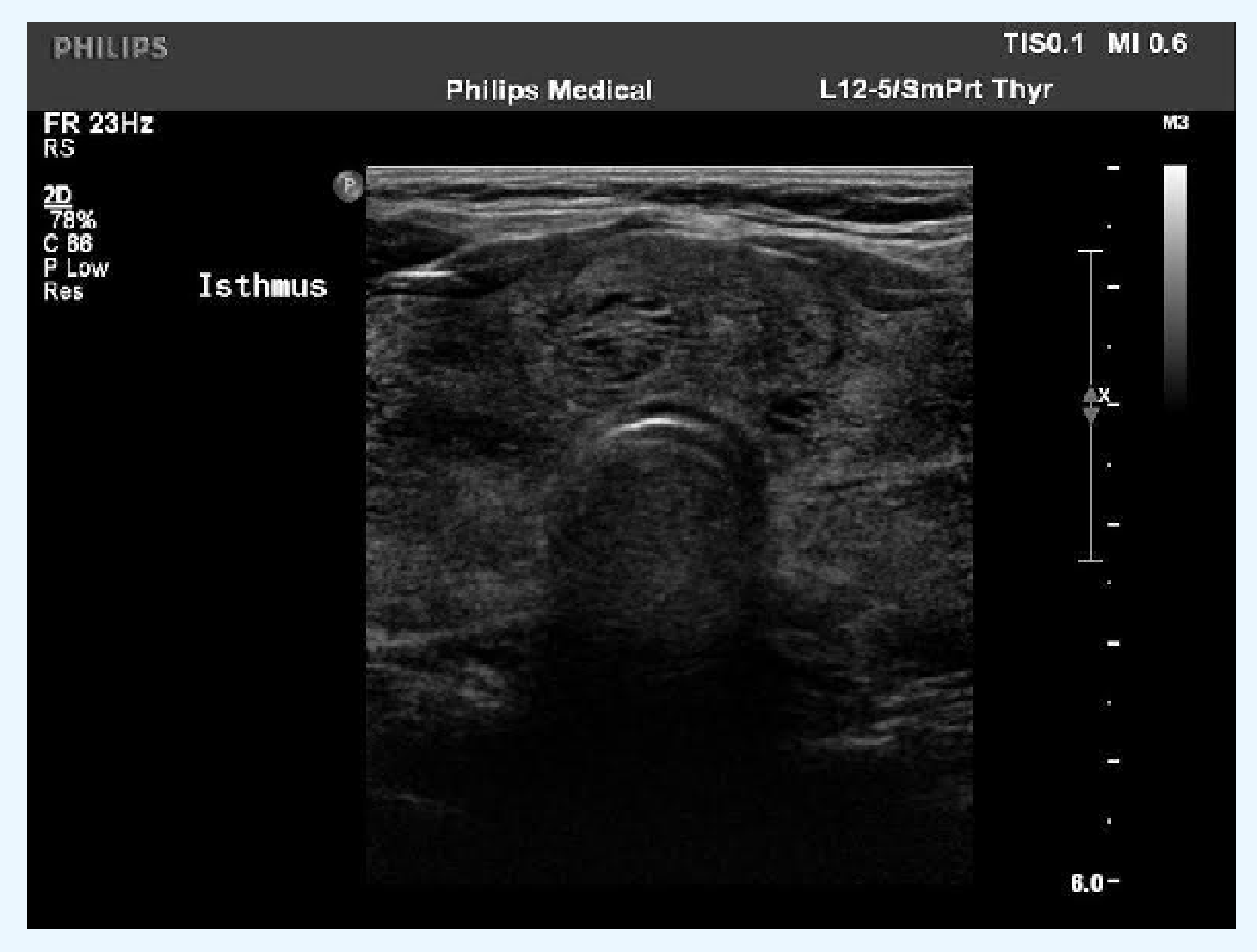

Image 1

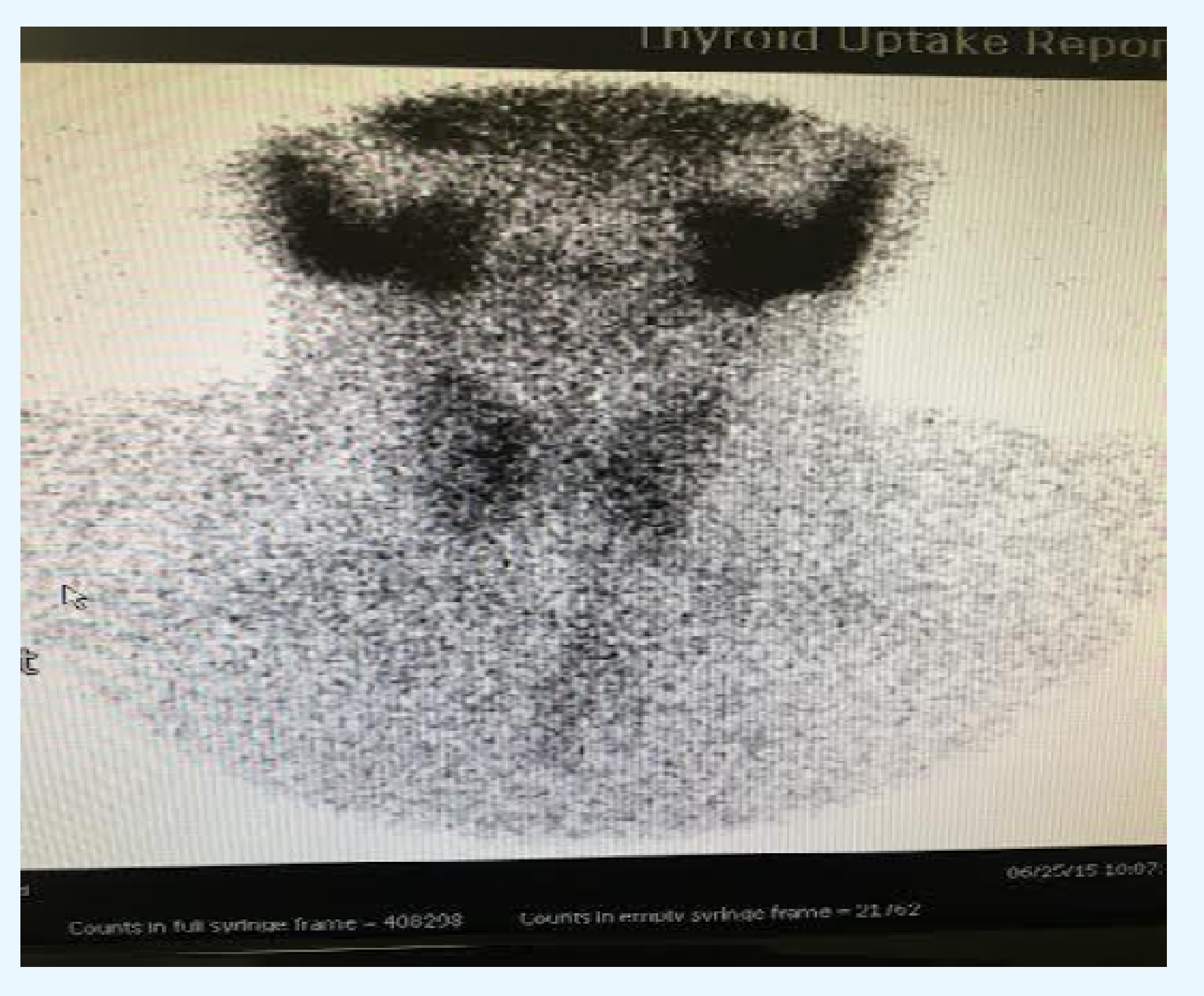

Image 2

Her Hyperthyroidism again spontaneously resolved after Lenalidomide was stopped following completion of 6 cycles of chemotherapy.

Lenalidomide is increasingly used in the treatment of myelodysplastic syndromes. Treating physicians must be aware of potential thyroid dysfunction associated with lenalidomide treatment(2). Checking thyroid function before starting the treatment and throughout the course is recommended.

1.Kotla V, Goel S, Nischal S, Heuck C, Vivek K, Das B, Verma A.Mechanism of action of lenalidomide in haematological malignancies .J Hematol Oncol 2009 12:36.

2. Hamnvik OP, Larsen PR, Marqusee E . Thyroid dysfunction from antineoplastic agents. J Natl Cancer Inst 2011 103:157287. 